\title{
Cerebral vasomotor reactivity in border zone infarcts; a transcranial Doppler study
}

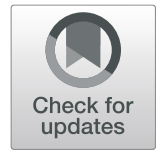

\author{
Afify Hossam (10, Shahinaz M. Helmy, Lobna M. El-Nabil, Naglaa M. El-khayat, Nevine M. El Nahas and \\ Magd F. Zakaria
}

\begin{abstract}
Background: Many reports have emphasized that watershed infarcts are the consequence of hemodynamic compromise, but other reports have suggested that this is not always the case and have suggested that embolization plays a major role in the development of watershed infarcts. Impaired cerebral vasomotor reactivity has certain correlates in watershed hypoperfusion strokes.

Objectives: This study aimed to assess the role of vasomotor reactivity impairment in watershed infarcts by transcranial Doppler. It also recorded correlates associated with impaired vasomotor reactivity in such patients.

Methodology: Sixty patients with watershed infarction after more than 1 month from onset were studied and grouped into three groups (14 patients with mixed internal and external watershed, 28 patients with internal watershed and 18 patients with external watershed infarcts). Magnetic resonant imaging and angiography of brain, carotid duplex, and echocardiography were done. $\mathrm{CO}_{2}$ reactivity to assess vasomotor reactivity was determined using Doppler.

Results: Cerebral vasomotor reactivity was impaired significantly among the internal watershed group compared with the external watershed group ( $P$ value $=0.040$ ). In external watershed infarcts, the anterior external watershed group showed significant impairment of vasomotor reactivity compared to posterior external watershed group ( $P$ value $=0.046)$. Impaired cerebral vasomotor reactivity was more evident in diabetic patients and not statistically related with other risk factors. It was also associated with middle cerebral artery stenosis.
\end{abstract}

Conclusion: The hemodynamic impairment is related to internal watershed more than external watershed infarcts, also it is more associated with anterior than posterior external watershed infarcts. Diabetes mellitus is the most correlated cerebrovascular risk factor associated with impaired vasomotor reactivity in such patients.

Keywords: Cerebral vasomotor reactivity, Hemodynamic impairment, Trans cranial Doppler, Watershed infarction

\section{Introduction}

Border zone or watershed (WS) hypoperfusion infarcts occur in cerebral areas between adjacent nonanastomosing arterial territories. Studies describe two wellknown hypo perfusion areas, one between the cortical areas supplied by the anterior cerebral artery (ACA), middle cerebral artery (MCA), and posterior cerebral artery (PCA). The other one lies in the deep areas along and slightly above the lateral ventricle, between the deep and the superficial branches of the MCA. The former, cortical areas were named as the external watershed (EWS), and the latter were named as the internal watershed (IWS) [1] .

\footnotetext{
* Correspondence: hafify@med.asu.edu.eg

Neuropsychiatry Department, Faculty of Medicine, Ain Shams University, Cairo, Egypt
}

Many studies have concluded that watershed infarcts occur due to hemodynamic compromise, but other reports have stated that this is not always the case and have suggested that embolization plays a major role in the development of watershed infarcts, also some studies have indicated that both mechanisms play a role in the pathogenesis of border zone infarction (reduced cerebral perfusion may impair the washout of micro-emboli) [2]. Studying the state of autoregulatory vasodilation reflects cerebrovascular reserve; that represent a prognostic factor in cerebrovascular insufficiency [3]. Transcranial Doppler (TCD) can evaluate cerebral vasomotor reactivity using $\mathrm{CO}_{2}$ or acetazolamide to stimulate cerebral vasodilatation; cerebral vasomotor reactivity (CVR) is then assessed from 
the cerebral blood flow $(\mathrm{CBF})$ or blood velocity change before and after the vasodilatory tool [3].

This study was previously presented as a poster presentation at the European society of neurosonology and cerebral hemodynamics conference, 19-21 May 2017 in Berlin/ Germany [4].

\section{Objectives}

This study aimed to assess the role of vasomotor reactivity impairment in watershed infarcts using CVR assessment by TCD. It also assessed correlates associated with impaired CVR in our sample.

\section{Patients and methods}

Sixty patients diagnosed with watershed infarcts, in Ain Shams University Hospitals over a period of 1 year, were included in the study after at least 1 month from stroke onset to exclude the hemodynamic changes associated with acute stroke, and patients with main territorial infarction, insufficient acoustic window and poor general condition that interfere with their cooperation for CVR testing were excluded from the study. Magnetic resonance imaging of the brain was done; infarcts (on diffusion weighted at onset and fluid attenuated inversion recovery FLAIR) were classified as either external watershed zone (wedge shaped between the ACA and MCA or between the MCA and $\mathrm{PCA}$ ) or internal watershed (between the superficial and deep branches of MCA) [5], see Fig. 1.

TCD was done for all patients with assessment of $\mathrm{CO}_{2}$ reactivity in order to detect CVR using DWL multi-Dop X machine. Subjects were lying supine, and blood flow velocities were assessed using headset in middle cerebral arteries bilaterally through the temporal windows at rest (normocapnia). Blood flow velocities in both MCA were then assessed during hypercapnia (apnea test with the measurement of the breath-holding index, BHI). The breathholding technique was performed as follows [6]: after normal breathing of room air for around $5 \mathrm{~min}$, the base line mean blood flow velocity of MCA is measured (Vr). The patients were told to hold their breath after a normal inspiration for $30 \mathrm{~s}$ or as long as they can if they cannot withstand the $30 \mathrm{~s}$ completely (minimum of $20 \mathrm{~s}$ ). During the maneuver, the MCA mean blood velocity was under continuous follow. The mean blood velocity recorded at the TCD screen just after the end of the breath-holding period was recorded as the maximal recorded MCA mean blood velocity (Vbh). The duration of breath-holding was also saved. The BHI was calculated from those data as percent increase in MCA mean blood velocity recorded by breath-holding divided by seconds of breath-holding:

$[(\mathrm{Vbh}-\mathrm{Vr}) / \mathrm{Vr} \times 100] / S$ where $\mathrm{Vr}$ is the MCA best recorded mean blood velocity at rest before breath-holding, and $S$ equal to seconds of breath-holding. The value $<0.6$ will be regarded as abnormal. Figure 2 shows an example for flow velocity changes with breath-holding.

Patients with severe cardiac or pulmonary diseases not tolerating the examination and patients with contraindications to MRI were excluded.

All cases also were assessed for medical history, full lab with assessment for $\mathrm{HbA1c}$ and lipid profile, and have undergone magnetic resonance angiography (MRA), carotid duplex, and echocardiography.

The ethical committee for research in the Faculty of Medicine-Ain Shams University-approved the study. All patients signed informed consent about the nature of the study and data collected by authors.

\section{Statistical analysis}

All data were recorded, and statistical analysis was done using the IBM-SPSS (Statistical Package for Social Science) 16 th version. The results were tabulated, grouped, and statistically analyzed using the following statistical procedures:

1. Independent sample $t$ test $(\mathrm{t})$ : for comparison between means of two different groups of patients.
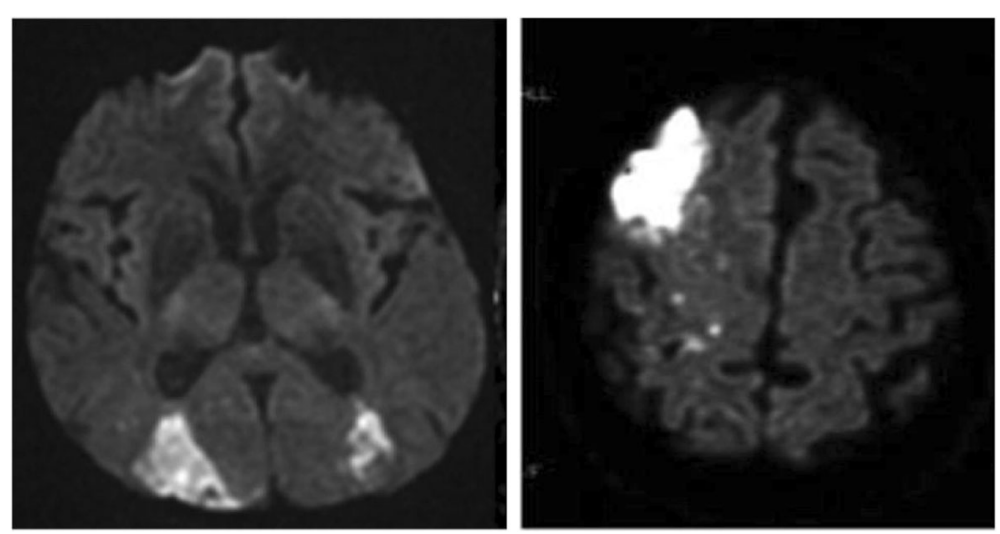

Fig. 1 Examples for water shed infarcts 

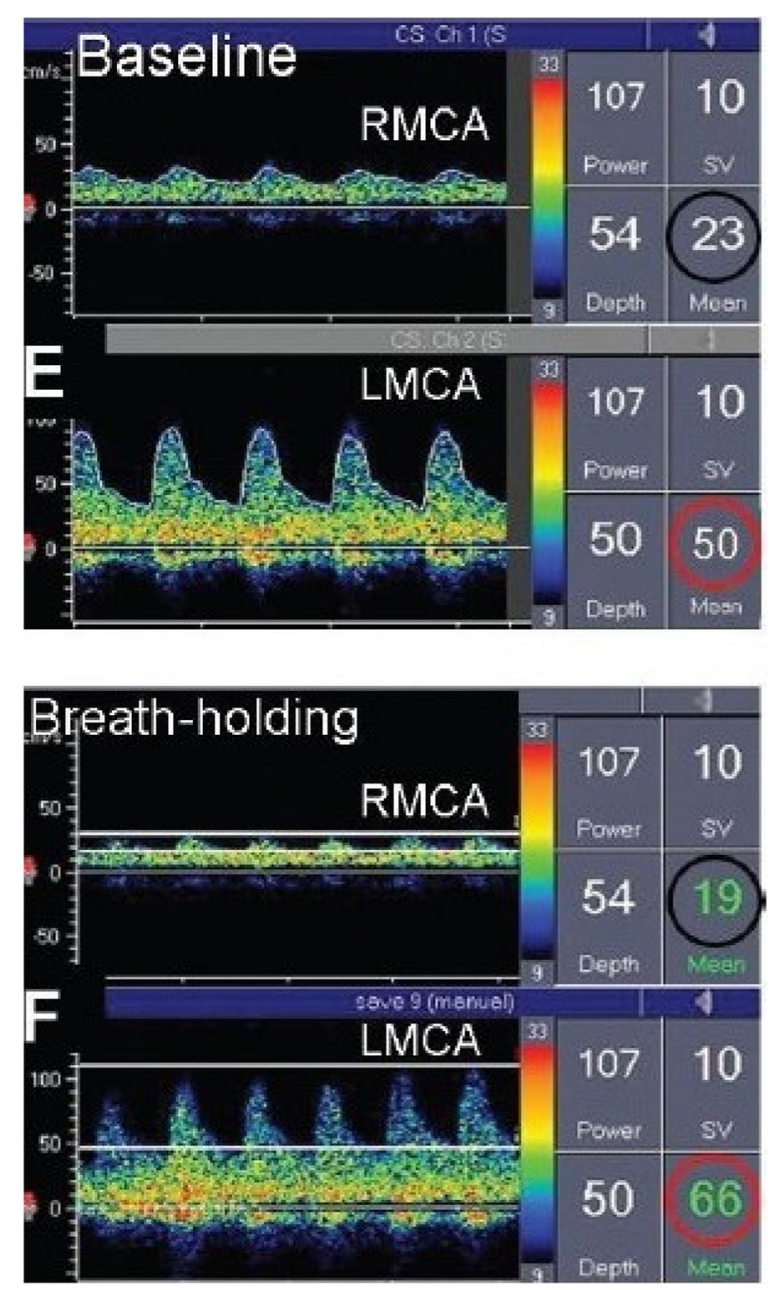

Fig. 2 TCD for assessment of CVR

2. One way ANOVA test (f): was used when comparing several means.

3. Pearson chi-square test $\left(X^{2}\right)$ : to detect whether there is a significant association between different categorical variables.

4. $P$ value: Used to indicate the level of significance: $P>$ 0.05 : insignificant, $P<0.05$ : significant, $P<0.01$ : highly significant.

\section{Results}

The study included 60 patients with watershed infarcts. The watershed infarcts pattern divided them into three groups, 28 patients with IWS, 18 patients with EWS, and 14 patients with mixed IWS and EWS. For analytical comparison in patients with watershed infarcts, we included the 46 patients with pure single pattern of watershed infarct(as mentioned 28 with IWS and 18 with EWS). These 46 patients included 18 males and 28 females, and the mean age was $53.17 \pm 12.53$, with age range from (27-76) years. Among the EWS group, eight patients had anterior EWS
Table 1 Risk factors and vascular status of internal and external watershed groups

\begin{tabular}{llll}
\hline & IWS (28) & EWS (18) & $\begin{array}{l}\text { Chi square test } \\
P \text { value }\end{array}$ \\
\hline Age & $55.93 \pm 11.85$ & $52.78 \pm 13.85$ & 0.415 \\
Sex $\quad$ Male & $10(35.7 \%)$ & $8(44.4 \%)$ & 0.553 \\
$\quad$ Female & $18(64.3 \%)$ & $10(55.6 \%)$ & \\
Smoking & $4(14.30 \%)$ & $2(11.10 \%)$ & 0.755 \\
DM & $16(57.10 \%)$ & $8(44.40 \%)$ & 0.400 \\
HTN & $22(78.6 \%)$ & $12(66.70 \%)$ & 0.370 \\
Dyslipidemia & $22(78.60 \%)$ & $10(55.60 \%)$ & 0.098 \\
Cardioembolic risk & $2(7.1 \%)$ & $2(11.1 \%)$ & 0.641 \\
ICA stenosis & $8(28.60 \%)$ & $2(11.10)$ & 0.161 \\
MCA stenosis & $10(35.70 \%)$ & $4(22.2 \%)$ & 0.332
\end{tabular}

(AEWS), eight patients had posterior EWS (PEWS), and two patients had both AEWS and PEWS infarcts. Patients were classified into two groups IWS and EWS groups according to MRI brain. There were no significant differences regarding age and sex among the two groups. Internal carotid artery (ICA) stenosis was more among IWS group $(28.6 \%)$ than EWS group $(11.1 \%)(P$ value $=0.161)$. Also, MCA stenosis was more among IWS group (35.7\%) than EWS group (22.2\%), yet the results did not reach a statistical significance. The different vascular risk factors did not correlate positively with either of watershed infarcts as shown in Table 1.

CVR was significantly impaired among IWS group (64.3\%) compared to EWS group (33.3\%) $(P$ value $=$ 0.040) as shown in Table 2. Regarding the impaired CVR among the subtypes of EWS group, anterior external watershed (AEWS) group showed significantly impaired CVR (75\%) when compared with posterior external watershed $($ PEWS $)$ group $(25 \%)(P$ value $=0.046)$ as shown in Table 3.

According to the CVR affection, the total number of 60 patients was classified into two groups; a group with impaired CVR and a group with preserved CVR. As regards the age and sex among the two groups, there was no statistically significant difference between them. As regards the risk factors among the two groups, the presence of DM had a statistically significant results, as it was higher among patients with impaired CVR being present in $20(62.5 \%)$ patients while it was present in eight (28.6\%) patients of the group with preserved CVR,

Table 2 Impaired CVR among internal and external watershed groups

\begin{tabular}{|c|c|c|c|c|c|}
\hline & \multicolumn{2}{|l|}{ IWS } & \multicolumn{2}{|c|}{ EWS } & \multirow{2}{*}{$\begin{array}{l}\text { Chi square } \\
P \text { value }\end{array}$} \\
\hline & No. & $\%$ & No & $\%$ & \\
\hline Impaired CVR & 18 & $64.3 \%$ & 6 & $33.3 \%$ & 0.040 \\
\hline
\end{tabular}


Table 3 Impaired CVR among anterior and posterior external watershed groups

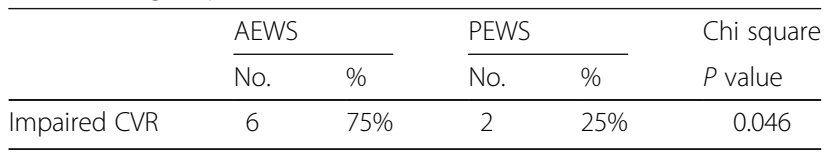

and this was statistically highly significant $(P$ value $=$ 0.009). Other risk factors (HTN, smoking, dyslipidemia) did not show a statistically significant difference between both groups. These results are shown in Table 4 .

The presence of ICA stenosis was found to be more in the group with impaired CVR $(n=10,31.2 \%)$ than in the group with preserved CVR $(n=6,21.4 \%)$, yet this was not statistically significant $(P$ value $=0.391)$. While the presence of MCA stenosis was more among the group with impaired CVR ( $n=16,50 \%)$, than the group with preserved CVR ( $n=4,14.3 \%)$, and this was statistically highly significant $(P$ value $=0.003)$.

\section{Discussion}

The underlying pathology of cerebral infarcts in the watershed area between the large cerebral vessels has been a point of debate [2]. Hypoperfusion and microembolization looked like two alternating exclusive pathophysiological methods that were introduced to explain the nature of watershed infarction in patients with cerebrovascular disease. For a long time, hypoperfusion and embolism were considered to be separate from each other. Recently, however, it has been thought that these two mechanisms might not be as independent from one another as was considered [1].

In the current study, the aim was to assess the vasomotor response hemodynamic impairment among patients with different subtypes of watershed infarctions, through the evaluation of cerebral vasomotor reactivity using TCD. We found that $\mathrm{CO}_{2}$ reactivity was significantly impaired among the IWS (64.3\%) than the EWS $(33.3 \%)$ groups, $(p=0.04)$; thus, hemodynamic impairment was thought to be related strongly to the pathogenesis of IWS infarcts, and this could not be applied to EWS. These results were in favor with many studies that found hemodynamic impairment to be more related to IWS infarcts than EWS. A previous study which evaluated the association between cerebral vasomotor reactivity (assessed by TCD and $\mathrm{CO}_{2}$ inhalation) and the prevalence and volume of watershed infarcts, found that there were significant increase in prevalence and volume of IWS infarcts in hemisphere with impaired $\mathrm{CO}_{2}$ reactivity compared to normal hemisphere, and no significance was found among EWS infarcts [7]. And these findings were also supported by many other studies [8-10]. On the contrary to our hypothesis, a previous study which assessed 30 patients with acute ischemic stroke and MCA stenosis, using TCD for microembolic signal detection, found that $50 \%$ of borderzone patients or combined borderzone and cortical infarcts had microembolic signal detection, compared with $14.3 \%$ for patients with nonwatershed infarcts [11]. These results were taken towards the embolic etiology among watershed patients. Another study found that internal watershed infarction could either be due to hemodynamic impairment or microembolism [12].

The more susceptibility of the IWS to a decline in cerebral perfusion has been related to the anatomical characteristics of cerebral arterioles at this site. The perforating medullary arteries from the pial arteries that reach the IWS area are the most distal branches of the ICA, and perfusion pressure is likely to be the lowest in these distal arteries. In addition, lenticulostriate arteries have poor collateral blood supply. Perfusion studies have affirmed that paraventricular white matter is liable to hemodynamic changes in patients with carotid artery atherosclerotic disease. The EWS area are at cortical sites, where penetrating arteries originate, and can have collateral supply through leptomeningeal and dural anastomoses, which protect it from effect of hypoperfusion [5].

Regarding the EWS infarcts, our results suggested that CVR impairment is significantly associated with AEWS more than PEWS $(P=0.046)$, and many studies suggested that AEWS are more susceptible to hemodynamic changes than PEWS infarcts; in agreement with this observations, most EWS infarcts observed in combination with IWS infarcts, involved the AEWS area, this relative vulnerability of the AEWS area may be because the MCA and ACA are both supplied only by the ICA, so critical stenosis or occlusion of the ICA will exert its maximum effect on this area [1].

Table 4 Comparison between the impaired CVR group and the preserved CVR group as regard the risk factors

\begin{tabular}{|c|c|c|c|c|c|c|}
\hline & \multicolumn{2}{|c|}{ Patients with impaired CVR (No. $=32)$} & \multicolumn{2}{|c|}{ Patients with preserved CVR $\left(\mathrm{No}_{\mathrm{O}}=28\right)$} & \multicolumn{2}{|c|}{ Chi square test } \\
\hline & No. & $\%$ & No. & $\%$ & $x^{2}$ & $P$ value \\
\hline Smoking & 6 & $18.8 \%$ & 6 & $21.4 \%$ & 0.067 & 0.796 \\
\hline DM & 20 & $62.5 \%$ & 8 & $28.6 \%$ & 6.907 & 0.009 \\
\hline HTN & 24 & $75.0 \%$ & 20 & $71.4 \%$ & 0.097 & 0.755 \\
\hline Dyslipidemia & 24 & $75.0 \%$ & 18 & $64.3 \%$ & 0.816 & 0.366 \\
\hline
\end{tabular}




\section{Conclusion}

We found that internal watershed is significantly related to vasomotor reactivity impairment, while this relation could not be applied to external watershed infarction. Regarding the subtypes of EWS, it was found that AEWS infarcts are related more to vasomotor reactivity impairment than PEWS infarcts. On assessment of factors associated with impaired CVR in watershed infarction patients, it was correlated with DM and presence of MCA stenosis.

\begin{abstract}
Abbreviations
ACA: Anterior cerebral artery; BHI: Breath-holding index; CBF: Cerebral blood flow; $\mathrm{CO}_{2}$ : Carbon dioxide; CVR: Cerebral vasomotor reactivity; DM: Diabetes mellitus; EWS: External water shed; FLAIR: Fluid-attenuated inversion recovery; FV: Flow velocity; HDL: High-density lipoprotein; HTN: Hypertension; ICA: Internal carotid artery; IWS: Internal watershed; IWSI: Internal watershed infarction; LDL: Low-density lipoprotein; MCA: Middle cerebral artery; MRA: Magnetic resonance angiography; MRl: Magnetic resonance imaging: PCA: Posterior cerebral artery; T2WI: T2-weighted image; TCD: Transcranial Doppler; Vbh: Velocity breath-holding; Vr: Velocity rest; WS: Watershed
\end{abstract}

\section{Acknowledgements}

None.

\section{Funding}

Authors received no funds to complete their work, and they did it as part of their work in university hospitals.

\section{Availability of data and materials}

The datasets used and analyzed during the current study are available from the corresponding author on reasonable request.

\section{Authors' contributions}

Selection of patients was done by SH. Doppler records were performed by $\mathrm{HA}$ and $\mathrm{SH}$. The manuscript was written by HA. Revising the data of patients was performed by $L E, N E, N E$, and $M Z$. All authors read and approved the final manuscript.

\section{Ethics approval and consent to participate}

This study was approved by the ethical committee for research in Faculty of Medicine-Ain shams university in October 2012. All patients signed informed consent about the nature of the study and the data collected by the authors prior to enrollment in the study.

\section{Consent for publication}

Not applicable.

\section{Competing interests}

The authors declare that they have no competing interests.

\section{Publisher's Note}

Springer Nature remains neutral with regard to jurisdictional claims in published maps and institutional affiliations.

Received: 9 February 2018 Accepted: 28 May 2019

Published online: 15 July 2019

\section{References}

1. Momjian I, Baron JC. The pathophysiology of watershed infarction in internal carotid artery disease. Stroke. 2005;36:567-77.

2. Forster A, Szabo K, Hennerichi MG. Mechanisms of disease: pathophysiological concepts of stroke in hemodynamic risk zones- do hypoperfusion and embolism interact? Nat Clin Pract Neurol. 2008:4:216-25.

3. Naqvi J, Yap K, Ahmad G, Ghosh J. Transcranial Doppler ultrasound: a review of the physical principles and major applications in critical care .Int J Vasc Med.;2013:629378. https://doi.org/10.1155/2013/629378.
4. Afify H, Helmy S, Zakaria M, Elkhayat N, Elnabil L. P25: cerebral vasomotor reactivity INBORDER-zone infarcts; a transcranial DOPPLER study. Int J Stroke. 2017;12(1S):35.

5. Mangla R, Kolar B, Almast J , Ekholm SE. Border zone infarcts: Pathophysiologic and imaging characteristics. Radiographics. 2011;315: 1202-13.

6. Herzig R, Hlustik P, Skoloudik D, Sanak D, Vlachova I, Herman M, et al. Assessment of the cerebral vasomotor reactivity in internal carotid artery occlusion using a transcranial Doppler sonography and functional MRI. J Neuroimaging. 2008;18:38-45.

7. Bisschops R, Klijn C, Kappelle J, Van Huffelen AC, Van der Grond J. Association between impaired carbon dioxide reactivity and ischemic lesion in arterial border zone territories in patients with unilateral internal carotid artery occlusion. Arch Neurol. 2003;60:229-33.

8. Derdeyn CP, Khosla A, Videen TO, Fritsch SM, Carpenter DL, Grubb RL, et al. Severe hemodynamic impairement and borderzone region. Radiology. 2001; 220:195-201.

9. Bisschops R, Klijn C, Kappelle J, Van Huffelen AC, Van der Grond J. Collateral flow and ischemic brain lesions in patients with unilateral carotid artery occlusion. Neurology. 2003;60:9.

10. Yong SW, Bang OY, Lee PH, Li WY. Internal and cortical border-zone infarction clinical and diffusion-weighted imaging features. Stroke. 2006;37: $841-6$.

11. Wong KS, Gao S, Chan YL, Hansberg T, Lam WW, Droste DW, et al. Mechanisms of acute cerebral infarctions in patients with middle cerebral artery stenosis: a diffusion-weighted imaging and microemboli monitoring study. Ann Neuro. 2002;52:74-81.

12. Moustafa RR, Izquierdo-Garcia D, Jones PS, Graves MJ, Fryer TD, Gillard JH, et al. Watershed infarcts in transient ischemic attack/minor stroke with $>50 \%$ carotid stenosis hemodynamic or embolic. Stroke. 2010;41:1410-6.

\section{Submit your manuscript to a SpringerOpen ${ }^{\circ}$ journal and benefit from:}

- Convenient online submission

- Rigorous peer review

- Open access: articles freely available online

- High visibility within the field

- Retaining the copyright to your article

Submit your next manuscript at $\boldsymbol{\nabla}$ springeropen.com 